\title{
Pulmoner Hipertansiyon ve Hemşirelik Bakımı
}

\author{
Serap Ünsar, ${ }^{1} \odot$ Özlem Özdemir, ${ }^{2} \odot$ Ecehan Yenici Bulut ${ }^{3}$ \\ ${ }^{1}$ Trakya Üniversitesi Sağlık Bilimleri Fakültesi, Hemşirelik Bölümü, İç Hastalıkları Hemşireliği Anabilim Dalı, Balkan Yerleşkesi, \\ Edirne, Turkey \\ ${ }^{2}$ Kırklareli Üniversitesi Sağlık Yüksekokulu, Sağlık Yönetimi Bölümü, Kırklareli, Turkey \\ ${ }^{3}$ Kırklareli Devlet Hastanesi, Palyatif Bakım Kliniği, Kırklareli, Turkey
}

\begin{abstract}
Özet
Pulmoner hipertansiyon vasküler değişiklikler ile karakterize ilerleyici bir hastalıktır. Pulmoner arterlerin proliferasyonu ve vazokonstriksiyonu sağ kalp yetersizliğine ve ölüme yol açmaktadır. Hastalar genellikle başlangıçta nefes darlığı, halsizlik, yorgunluk ve ödem gibi semptomlar deneyimlerken geç dönemlerinde senkop, presenkop görülebilmektedir. Bu semptomlar diğer kardiyopulmoner hastalıkları taklit etmekte ve pulmoner hipertansiyonlu hastalarda tanı koymada gecikme olmaktadır. Pulmoner hipertansiyon kronik bir hastalık olup, günlük yaşamı sınırlamakta ve hastalar yaşam kalitesini azaltan birçok semptomla karşı karşıya kalmaktadır. Mevcut tüm medikal tedavi ve bakım karmaşık olup büyük oranda palyatiftir. Tedavinin ve bakımın amacl; morbidite ve mortaliteyi azaltmak, semptomları ve fonksiyonel durumu iyileştirmektir. Pulmoner hipertansiyon vakalarında hastaneye sık yatışlar olmaktadır. Hemşireler; pulmoner hipertansiyon açısından yüksek risk taşıyan hasta gruplarını bilmelidir. Hemşireler pulmoner hipertansiyonda hasta ve hasta yakınlarının eğitiminde, hasta bakımında, medikal tedavinin uygulanmasında, semptom yönetiminde ve hasta takibinde önemli rollere sahiptir. Bu makale pulmoner hipertansiyonun etiyolojisi, sınıflandırılması, patofizyolojisi, tedavi ve bakımını sunmak amacıyla yazıldı.
\end{abstract}

Anahtar sözcükler: Hemşirelik bakımı; pulmoner hipertansiyon; tedavi.

\section{Pulmonary Hypertension and Nursing Care}

\section{Abstract}

Pulmonary hypertension is a progressive destructive disease characterized by vascular changes. Proliferation and vasoconstriction of pulmonary arteries lead to right heart failure and death. While patients usually have symptoms, such as dyspnea, fatigue, weakness and edema, at the beginning, the syncope and presyncope can be observed in late periods. The mentioned symptoms imitate other cardio-pulmonary diseases and a delay occurs in establishing a diagnosis in patients with pulmonary hypertension. Pulmonary hypertension is a chronic disease, restricts the daily life and the patients face with many symptoms which reduce quality of life. All of the current medical treatments and cares of the patients are complicated and are largely palliative. The aim of treatment and care of the patients is to decrease morbidity and mortality and to heal symptoms and functional situation. Frequent hospitalization occurs in pulmonary hypertension cases. Nurses should know the high risk-bearing patient groups in terms of pulmonary hypertension. Nurses have important roles in training of patients and patient relatives, care of patients, administration of medical treatment, symptom management and patient follow-up in pulmonary hypertension. In this 


\begin{abstract}
rewiev was discussed in order to present etiology, classification, pathophysiology, treatment and care of pulmonary hypertension.

Keywords: Nursing care; pulmonary hypertension; treatment.
\end{abstract}

Cite this article as: Ünsar S, Özdemir Ö, Yenici Bulut E. Pulmonary Hypertensıon and Nursıng Care. Turk J Cardiovasc Nurs 2019;10(21):17-24

$\mathrm{P}$ ulmoner hipertansiyon $(\mathrm{PH})$ yavaş ilerleme gösteren daha çok genç kadınlarda görülen, çoğu kez geç dönemde teşhis edilen kronik ve ilerleyici bir hastalıktır. ${ }^{[1]} \mathrm{PH}$, progresif bir özellik göstererek ilerleyen dönemlerde sağ kalp yetersizliğine ve ölüme neden olabilir. ${ }^{[2]}$

Dünyadaki PH'nin kesin prevalansı bilinmemektedir. Avrupa ve $A B D$ çalışmalarında tahmini yıllık pulmoner hipertansiyon insidansı, genel nüfusta yılda milyon kişi başına 2-8 vaka arasındadır. ${ }^{[3,4]} \mathrm{PH}$ 'ı hastaların güncel özelliklerini belirlemek, tanı ve tedaviyi iyileştirmek amacıyla 2006 ve 2009 yılları arasında 55 merkezde 3.515 hasta ile yapılan The Registry to Evaluate Early and Long-term pulmonary arterial hypertension disease management (REVEAL) araştırmasında hastaların \%79.5'i kadın, tahmini insidansı milyonda 2.0 vaka ve prevalansı milyonda 10.6 vaka olarak bildirilmiştir. ${ }^{[4,5]}$ Fransa'da 674 PH hastası ile yapılan çalışmada insidansının 2.4 vaka/1 milyon yetişkin nüfusu olarak saptanmıştır. Bir yıllık sağ kalım, olay kohortunda \%88 olarak rapor edilmiştir. ${ }^{[6]}$ Türk toplumunda erişkin tip PH ile ilgili yapılan epidemiyolojik çalışmada hastaların \%68.4'ünün kadın olduğu, primer pulmoner hipertansiyonun yıllık prevalansının bir milyonda 9,6 vaka, sekonder pulmoner hipertansiyonun yıllık prevalansı ise bir milyonda 6 vaka olduğu tespit edilmiştir. ${ }^{[7]}$

Son yıllarda $\mathrm{PH}^{\prime}$ un tedavisinde önemli gelişmeler kaydedilmiş olmasına rağmen mevcut tüm medikal tedaviler sınırlı semptomatik yarar sağlamaktadır. ${ }^{[8]} \mathrm{PH}$ olan hastalar başlangıçta özellikle yorgunluk ile birlikte dispneden şikayet ederler. Diğer kardiyopulmoner hastalıkları taklit eden semptomlar giderek kötüleşir ve hastalığın tanısı gecikebilir. ${ }^{[9]} \mathrm{Bu}$ semptomlar ciddi olup hastaların fonksiyonlarını ve yaşam kalitelerini etkilemektedir. $\mathrm{PH}^{\prime} \mathrm{lu}$ bireyler yaşam kalitesinde ciddi bozulma yaşamaktadır. ${ }^{[10]}$ Çalışmalarda $\mathrm{PH}$ hastalarının sağlıkla ilgili yaşam kalitesinin önemli ölçüde bozulduğu ve hastalarda anksiyete ve depresyon gibi ruhsal bozuklukların sık olduğu bildirilmiştir. ${ }^{[10,11,12]}$ Hastalığın şiddeti ve tedavinin karmaşıklığı nedeniyle hastaneye sık yatışlar olmaktadır. ${ }^{[13]}$ Türkiye ulusal PH kayıt çalışması "SiMURG" Registry on clinical outcome and survival in pulmonary hypertension groups anket verilerine göre 1501 hasta izlenmiş ve yıllık yatış oranı $\% 14.9 \pm 19.5$ olarak tespit edilmiştir. ${ }^{[14]}$

\section{Tanım ve Sınıflandırma}

Normal sağlıklı bireylerde sistolik pulmoner arter basınCl 22-30 mmHg, diyastolik pulmoner arter basıncı 9-22 $\mathrm{mmHg}$ ve ortalama pulmoner arter basıncı (PAB) 15-18 $m m H g$ dır. ${ }^{[1]}$ Sağ kalp kateterizasyonu ile dinlenme halinde değerlendirilen $P A B$ ortalamasının $25 \mathrm{mmHg}$ veya daha üzerine çıkması durumunda $\mathrm{PH}$ 'dan söz edilir. ${ }^{[15,16]} \mathrm{PAB}$ rakamsal değeri arttıkça hastalığın şiddeti de artmaktadır. PAB 25-45 mmHg arası hafif düzey, $45-65 \mathrm{mmHg}$ orta ve 65 üstünde olan sonuçta ağır PH gösterir. ${ }^{[1]}$ Sağ kalp kateterizasyonu ile egzersiz sırasında değerlendirilen ortalama PAB değerinin $30 \mathrm{mmHg}$ üstünde olması şeklinde tanımlanması yayımlanmış verilerle desteklenmemektedir ve sağlıklı kişilerde bu değerlerden daha yüksek değerlerle karşılaşılabilmektedir. Bundan dolayı günümüzde egzersiz sırasında sağ kalp kateterizasyonu ile değerlendirilen $\mathrm{PH}$ için herhangi bir tanım bulunmamaktadır. ${ }^{[15]} \mathrm{PH}$ iki kategoriye ayrılmıştır: primer $\mathrm{PH}$ ve sekonder $\mathrm{PH}$, belirlenen risk faktörlerinin varlığına dayanmaktadır. Benzer patolojik bulguları, hemodinamik özellikleri ve tedavi yönetimi stratejilerini paylaşan $\mathrm{PH}$ formlarını kategorize etmek için 5 klinik sınıflama geliştirilmiştir. Bu ana sınıflandırma;

Grup I. : Pulmoner arteriyel hipertansiyon (PAH),

Grup II: Sol kalp hastalıklarına bağlı PH,

Grup III: Akciğer hastalıklarına ve/veya hipoksiye bağlı PH

Grup IV: Kronik tromboembolik PH (KTEPH)

Grup V: Mekanizmaları belli olmayan ya da çok faktörün sebep olduğu PH. ${ }^{[15,17]}$

SiMURG çalışmasında PH'nun en sık görüldüğü grup \%69 Grup-1, ardından \%19'u Grup IV, \%8'i Grup III ve \%4 ile kombine pre- ve post-kapiller PH oluşturmaktadır. Grup I'in kendi içindeki genel dağılımına bakıldığında ise \%34 İdiyopatik PAH, \%0.4 ailesel, \%47 Konjenital kalp hastalığı ve \%19'u bağ doku hastalığı ile ilişkili pulmoner hipertansiyon oluşturmaktadır. ${ }^{[14]}$

\section{Fizyopatoloji}

Pulmoner hipertansiyonun fizyopatolojisi karmaşık bir yapıya sahip olup, vazokonstrüksiyon, vasküler remodelling ve trombozdan oluşan temel faktörler üzerinde yoğunlaşmaktadır. PH ile görülen patofizyolojik değişiklikler, vazokonstriksiyon yoluyla pulmoner arter genişliğinde azalma, intimal proliferasyon ve fibrozdur. ${ }^{[1,18]} \mathrm{PH}$ pulmoner arteriyel dolaşıma kısıtlı kan akışından kaynaklanır ve pulmoner vasküler rezistansta (PVR) artışla sağ kalp yetersizliği ile sonuçlanır. Pulmoner arter düz kas hücrelerindeki proliferasyon nedeniyle intravasküler lümen çapı azalır. Pulmoner arter basıncında ve pulmoner vasküler dirençte (PVR) 
artma olur. Azaltılmış apopitoz veya programlanmış hücre ölümü meydana gelir. Endotel disfonksiyonu endotel üretiminde değişikliklere neden olur. Prostacyclin'e neden olan azalmış bir üretim vazokonstriksiyona sebep olur. Endotelin 1 artmıştır ve bu durum vazokonstriksiyon ve trombosit agregasyonuna neden olur. Nitrik oksit ve prostacyclinde azalma PH'da vazokonstriksiyon ile sonuçlanır. Nörohormonal sistemin aktivasyonu ile sempatik sinir sistemi ve renin-anjiyotensin-aldesteron sistemi vazokonstriksiyona ve sodyum retansiyonuna neden olur. ${ }^{[9]}$ Hastalık ilerledikçe pulmoner hipertansiyonun derecesi artar; kalp debisi azalır. [1] Sağ ventrikül afterload artışı, stroke volüm ve sağ ventrikül ejeksiyon fraksiyonunda azalma görülür. Çünkü sağ ventrikül miyokardı sol ventrikül duvarından daha incedir, basınç artışı miyokardiyal oksijen ihtiyacına neden olur ve sağ ventrikül hipertrofisi gelişir. Sağ ventrikül dilatasyonu sıvı retansiyonu ile sonuçlanır. ${ }^{[9]}$

\section{Etiyoloji}

$\mathrm{PH}$ etiyolojisi tam olarak bilinmemektedir. Hastalık ailesel ve sporodik olarak ortaya çıkabilmektedir. ${ }^{[2]}$ Ailesel pulmoner hipertansiyon otozomal dominant geçiş gösterir. ${ }^{[1]} \mathrm{Ka}$ lıtımın bu tipinde ard arda gelen kuşaklarda hastalığın kötüleşmesi söz konusudur. PH ile ilişkili olan gen 2q31-32'nin 27 sentimorgan bölgesinde lokalizedir. ${ }^{[2]}$ İspanya'da yasal olmayan şekilde yemek pişirmede kullanılan kolza tohumu yağının kullanılması epidemik PH ile sonuçlanmıştır. ${ }^{[19]}$ |̧̧̇tah kesiciler ile $\mathrm{PH}$ arasında ilişki olduğu düşünülmektedir. Fransa'da yapılan bir çalışmada iştah kesici ilaçların (esas olarak fenfluramin türevleri) kullanımı primer pulmoner hipertansiyon riskinin artması ile ilişkili olduğu bulunmuştur. [20] $\mathrm{PH}$ 'un diğer nedenleri arasında raynaud hastalığı, skleroderma, sistemik lupus eritematozus, insan immün yetersizliği virüs enfeksiyonu (HIV), tiroid hastalıkları, gebelik, kronik hemolitik anemi, iştah azaltıcı ve kemoterapi ajanları gibi bazı ilaçlar yer almaktadır. ${ }^{[18]}$

\section{Belirti Bulgular}

Semptomların başlangıcı genellikle sinsidir. ${ }^{[2]} \mathrm{PH}^{\prime}$ lu hastalar erken dönemde asemptomatiktir. ${ }^{[1]}$ Semptomlar; bozul- muş oksijenasyona ve etkisiz kardiyak outputa bağlı olarak daha çok nefes darlığı ve efor dispnesi, göğüs ağrısı, öksürük, yorgunluk ve baş dönmesidir. ${ }^{[18]}$ Hastalarda zamanla artan yorgunluk, palpitasyon, göğüs ağrısı ve artan egzersiz intoleransı, hipoksemi, presenkop veya senkop, hemoptizi, ani ölüm semptomlarından herhangi biri oluşabilir. ${ }^{[2,}$ ${ }^{21]}$ Gürses ve ark. ${ }^{[22]}$ retrospektif olarak yaptıkları bir çalışmada $\mathrm{PH}$ hastaların \% 83'ünde çabuk yorulma \%73'ünde dispne, \%13'ünde çarpıntı ve \%7'sinde hemoptizi olduğu bildirilmiştir.

Artan farkındalığa rağmen, genellikle semptomların başlangıcı ile pulmoner hipertansiyon tanısı arasında gecikme vardır. Altta yatan bilinen bir akciğer veya kardiyak bozukluk yok ise, ilk belirtiler ile tanı arasında 3 yıla kadar bir gecikme olmaktadır. ${ }^{[21]}$ Fransa'da PH hastalar ile yapılan çalışmada tanı anında hastaların \%75'nin New York Kalp Derneği fonksiyonel sınıf III/IV olduğu bildirilmiştir. ${ }^{[6]}$

$\mathrm{PH}$ fizik muayene bulguları genellikle başvuru sırasında ilerlemiştir. Bunlar; siyanoz, artmış juguler ven basıncı, sağ ventrikülde yüklenme, ikinci kalp sesinin pulmoner bileşeninde sertleşme ve şiddetinde artma, triküspit yetersizliği ve veya pulmoner yetersizliğe ait üfürümler, hepatomegali, asit ve periferik ödemdir. ${ }^{[2,21]}$ Hastalığın progresyonunun takibinde, tedaviye yanıtın izlenmesinde fonksiyonel sınıflandırma Tablo 1'de sunulmuştur. ${ }^{[1,15]}$

\section{Tanı}

$\mathrm{PH}$, çeşitli komorbid durumlar ile ilişkili olabileceğinden, geçmiş tıbbi öyküsü önemli yer tutar. Hastalarda toksik ajanlara maruziyet, iștah kesici ve kemoterapi ajanlarının (mitomisin-C, karmustin, etoposid, siklofosfamid ve bleomisin dahil) kullanımı, HIV enfeksiyonu, pulmoner emboli veya derin ven trombozu öyküsü ayrıntılı bir şekilde sorgulanmalıdır. ${ }^{[21]}$

\section{Elektrokardiyogram}

Elektrokardiyogram (EKG), $\mathrm{PH}$ için etkili bir tarama aracı olarak kullanmak için yeterli duyarlılığa sahip değildir. Bununla birlikte, aritmi varlığı prognoz hakkında bilgi sağlar. ${ }^{[21]} \mathrm{PH}$

\footnotetext{
Tablo 1. Pulmoner hipertansiyon işlevsel sınıflandırması DSÖ Fonksiyonel Sınıflaması (DSÖ-FS)

SINIF I PH mevcut olan fakat olağan fiziksel aktiviteler sırasında, nefes darlığı, halsizlik, yorgunluk, göğüs ağrısı ve senkop oluşmuyor.

SINIF II Fiziksel aktivitelerinde hafif düzeyde kısıtlama oluşan PH'lu hastalarda normal günlük aktivitede nefes darlığı, göğüs ağrısı, senkop oluşur.

SINIF III Fiziksel aktivitesinde belirgin kısıtlama oluşan $\mathrm{PH}^{\prime}$ lu hastalar istirahatte rahattırlar, normal sıradan aktivitelerin daha azında bile nefes darlığı, göğüs ağrısı, yorgunluk, halsizlik, senkop oluşur.

SINIF IV Semptomsuz hiçbir fiziksel aktiviteyi gerçekleştiremezler. Sağ kalp yetersizliği semptomları, bulguları vardır. İstirahatte nefes darlığı, yorgunluk olabilir. Küçük bir aktiviteyle bile semptomlar artar.
} 
hastalarının EKG değişiklikleri, \%87'sinde sağ ventrikül hipertrofisi ve \%79'unda sağ aks sapmasını içerir. ${ }^{[1,21]}$

\section{Göğüs Röntgeni}

Hastalığın erken dönemlerinde spesifik bulgular yoktur. Hastalık ilerledikçe PH'ı düşündüren bulgular, periferal pulmoner vasküler işaretlerin eşlik eden zayıflaması ile genişlemiş ana ve hiler pulmoner arteriyel gölgeleri içerir. ${ }^{[21]}$

\section{Ekokardiyografi}

PH'dan şüphelenildiğinde, pulmoner arter sistolik basıncı$\mathrm{nı}$, sağ ventriküler genişlemeyi, sağ atriyal genişlemeyi ve sağ ventrikül disfonksiyonunu değerlendirmek için ekokardiyografi kullanılmalıdır. [21]

\section{Solunum Fonksiyon Testleri}

PH tanısında, önemli akciğer hastalığını dışlamak için solunum fonksiyon testleri kullanılır. ${ }^{[21]}$

\section{Ventilüsyon-perfüzyon (V/Q) Akciğer Taraması}

V/Q akciğer taramaları, değerlendirmenin önemli bir bileşenidir ve PH'nun potansiyel olarak tedavi edilebilir bir nedeni olan kronik tromboembolik pulmoner hipertansiyonu dışlamak için yapılmalıdır. [21]

\section{Dakikalık Yürüme Testi}

6 dakikalık yürüme testi uygulanması teknik açıdan kolay, ucuz, tekrarlanabilir ve standartize edilmiş bir yöntemdir. [21] Test fonksiyonel durum ve egzersiz kapasitesi ile ilgili değerli bilgiler veren objektif bir ölçümdür. Testinin amaçları; maksimum egzersiz toleransının belirlenmesi; fonksiyonel kapasitenin belirlenmesi; egzersiz kapasitesinin temel bir ölçüsünü oluşturmak ve tedaviye yanıtı takip etmek olarak sıralanabilir. ${ }^{[1,21]}$ Bu testte yürünen mesafe, Borg skalası ile efor dispnesi ve parmaktan $\mathrm{O} 2$ satürasyonu değerlendirilir. 250 metreden daha az yürüme mesafesi kötü prognoz göstergesi olarak kabul edilir. ${ }^{[15]}$

\section{Sağ Kalp Kateterizasyonu}

Sağ kalp kateterizasyonu $\mathrm{PH}^{\prime} \mathrm{u}$ değerlendirmede, hemodinamik profilin ciddiyetini tespit etmede en çok kullanılan tanı yöntemidir. Sağ kalp kateterizasyonu PH varlığını doğrulamak, pulmoner venöz hipertansiyonun dışlanması dahil spesifik tanıyı oluşturmak, hemodinamik bozukluğun şiddetini belirlemek, pulmoner dolaşımı değerlendirmek ve tedaviyi yönlendirmek için gereklidir. ${ }^{[21]}$

\section{Laboratuvar Testleri}

Tüm hastalarda rutin biyokimya, seroloji, hematoloji ve tiroit fonksiyon testleri yapılmalıdır. ${ }^{[15]}$

\section{PH Tedavi}

PH'da yaşam süresi, bundan 20 yıl önce ortalama 2.8 yıl olarak kabul ediliyordu. ${ }^{[1]}$ Son 20 yılda tedavide önemli gelişmeler olmuş, hastaların sağ kalım ve fonksiyonel kapasiteleri iyileştirilmiştir. ${ }^{[23]} \mathrm{PH}$ hastalarında, hastalığın şiddetini önlemek, pulmoner vazodilatasyonu desteklemek ve ventriküler fonksiyonu en üst seviyeye çıkarmak için tedavi gereklidir. [24]

\section{PH'da tedavi hedefleri:}

- Semptomları azaltmak,

- Hemodinamiyi düzeltmek,

- Egzersiz kapasitesini arttırmak ve prognozu iyileştirmek,

- Yaşam kalitesini arttırmak,

- Mortalite ve morbiditeyi azaltmaktır. ${ }^{[25]}$

Semptomların tedavisini, tetikleyen faktörlerin engellenmesi, sıvı alımının azaltılması, mekanik ventilasyon uygulanması, vazopressör kullanımı oluşturmaktadır. Mekanik ventilatör desteğine ihtiyaç duyulması durumunda mümkün olduğunca endotrakeal entübasyondan kaçınılmalıdır. Sağ ventrikül yetersizliği gelişmiş ise tedavide;

1. Tetikleyici faktörlerin önlenmesi, tedavisi ve destek tedavisinin sağlanması,

2. Sıvı dengesinin ayarlanması,

3. Sağ ventrikül art yükünün azaltılması,

4. Kardiyak outputun düzeltilmesi,

5. Perfüzyon basıncının düzeltilmesi amaçlanmalıdır. ${ }^{[26]}$

Kalsiyum kanal blokerleri, prostanoidler, endotelin antagonistleri ve fosfodiesteraz 5 inhibitörleri tedavide önemli ilaçlardandır. ${ }^{[25]}$

\section{PH Tedavi Aşamaları:}

\section{Destek Tedavisi:}

a. Oral Antikoagülanlar: Pulmoner arter trombozunun önlenmesinde etkilidir. ${ }^{\text {[25] }}$

b. Diüretikler: Semptomların düzeltilmesinde dekompanse sağ kalp yetersizliğinde, karaciğerde dekonjesyona bağlı büyüme, asit ve periferik ödem geliştiği durumlarda endikedir. ${ }^{[15]}$

c. Oksijen: $\mathrm{PH}$ hastalarında oksijen uygulaması pulmoner vasküler dirençte azalma göstermekle birlikte uzun süre oksijen tedavisinin yararlı olduğunu gösteren yeterli çaIışma bulunmamaktadır. ${ }^{[15]}$

d. Digoksin: $\mathrm{PH}$ 'da akut olarak kalp debisini düzelttiği gösterilmiş ancak kronik uygulamada etkinliği kanıtlanmamıştır. ${ }^{[15,27]}$

\section{2. Özgül İlaç Tedavisi}

a. Kalsiyum Kanal Blokerleri: Akut vazoaktivite testi po- 
zitif olanlarda kullanılır. ${ }^{[15,25]} \mathrm{PH}^{\prime}$ da semptomları düzeltir, yaşam süresini ve kalitesini arttırır.

b. Prostanoidler: Tüm PAH formlarında kullanılır ${ }^{[25]}$ ve bütün damar yataklarında vazodilatasyon yapar. ${ }^{[15]}$

c. Eporostenol (Sentetik Prostasiklin): İdiyopatik pulmoner arteriyal hipertansiyon (IPAH) veya konnektif doku hastalığı ile ilişkili PAH olgularında, epoprostenol semptomları, yaşam kalitesi, egzersiz kapasitesi ve hemodinamiği iyileştirir.

d. İloprost: İnhalasyon yolu ile uygulandığında semptomları, egzersiz kapasitesini, fonksiyonel sınıflama, hemodimiği ve yaşam kalitesini düzeltir.

e. Treprositinil: Doza bağlı olarak 6 dakika yürüme mesafesinde (6 DYM) artışa neden olmaktadır. Semptomları, yaşam kalitesini düzeltir ve hemodinamiği iyileştirir.

f. Beraprost: Fonksiyonel iyileşme sağlar. New York Kalp Birliği fonksiyonel sınıflamasında (NYHA) II-III semptomları olan hastalarda etkili olduğu bulunmuştur. ${ }^{[1]}$

g. Endotelin Reseptör Antagonisti: Fonksiyonel sınıf I, II, III hastalarında endikedir. ${ }^{[25]}$

h. Bosentan: Egzersiz kapasitesinde, hemodinamik durumda ve klinik tabloda düzelme sağlamaktadır.

i. Sitaksentan: Yapılan çalışmalarda egzersiz kapasitesinde ve hemodinamik durumda iyileşme sağladığı bulunmuştur.

j. Ambrisentan: Kullanıldığı hastalarda hemodinamide, egzersiz kapasitesinde ve klinik tabloda iyileşme olduğu saptanmıştır.

k. Fosfodiesteraz tip-5 İnhibitörleri: Fonksiyonel sınıf II ve III'de endikedir. ${ }^{[15]}$

I. Sildenafil: Egzersiz kapasitesi, semptomlar ve hemodinamik durumda iyileşme sağlamaktadır. ${ }^{[15,28]}$

m. Tadalafil: En yüksek dozda egzersiz kapasitesi, hemodinami, semptomlar ve klinik tablonun iyileşmesinde faydalıdır. ${ }^{[15]}$

\section{PH'da Cerrahi Tedavi:}

a. Transplantasyon: Illaç tedavisine cevap vermeyen hastalar aday olabilir. Akciğer transplantasyonu; tek/ çift taraf akciğer transplantasyonu kalp transplantasyonu ile birlikte ya da ayrı yapılmaktadır. Tek akciğer transplantasyonu ile PAB azalır, belirtiler iyileşir, sağ kalp disfonksiyonu ve yetersizliği düzelir. ${ }^{[1]}$ Kalp akciğer transplantasyonu sonrası sağ kalım oranı $\% 40$ 'tır ve transplantasyona başvuru zamanı oldukça önemlidir. [28] Prognozu kötü olduğuna işaret eden özellikler saptanan ve DSÖ-FS III-IV olan hastalar transplantasyon listesine alınmak üzere sevk edilmelidir. ${ }^{[15,27]}$

b. Balon Atriyal Septostomi (BAS): Illeri evre PH'da uygu- lanır ve operasyonda mortalite yüksektir. Sağ ventrikül end-diyastolik basınç azalmakta, yaşam süresi uzamaktadır. $^{[1]} 6$ DYM'de iyileşme sağladığı gösterilmiştir. Fakat ağır sağ/sol yetersizlikte ve tekrarlı senkoplarda kontrendikedir. ${ }^{[27]}$

c. Pulmoner Tromboendarterektomi (TEA): $\mathrm{PH}^{\prime} \mathrm{l}$ hastalarda ana lob büyük segment arterlerindeki organize trombotik materyalin çıkarılmasıdır. TEA sonunda pulmoner hemodinami dramatik düzelir, NYHA I-Il olur, egzersiz kapasitesi artar, sağ ventrikül fonksiyonları düzelir. ${ }^{[1]}$

\section{Hastalık Yönetimi}

1. Sıvı Alımı: Hipervizkozite semptomları arttırabileceği ve böbrek fonksiyonlarını etkileyebileceğinden dehidratasyondan kaçınılmalıdır.

2. Egzersiz: $\mathrm{PH}$ hastalarının aktif kalmaları ve obeziteden kaçınmaları önemlidir. Hastalar yavaş yavaş kademeli ve düşük yoğunluklu aerobik egzersiz için teşvik edilmelidir. ${ }^{[28]}$ Ancak şiddetli nefes darlığı, sersemlik ve göğüs ağrısına neden olabilecek düzeyde efordan kaçınmalıdır. ${ }^{[15]}$

3. Beslenme: Özellikle sağ kalp yetersizliği riski olan PH hastalarına düşük sodyum içeren diyet önerilmelidir. ${ }^{[27]}$ Kaçınılması gereken sodyumdan yüksek gıdalar ve düşük sodyumlu yemeklerin nasıl hazırlanacağı konusunda diyetisyenden danışmanlık alınmalıdır. ${ }^{[9]}$

Pulmoner hipertansiyon, sağ ventrikül yetersizliğinin en sık nedenidir. Hipertrofiye edilmiş sağ ventrikülün oksidatif metabolizmasının artmış yük ile baş edebilmesi ve iskelet kaslarının fiziksel egzersiz yapması için demirin arttırılması önemli olduğundan, demir eksikliği pulmoner hipertansiyonda zararlı etkilere neden olabilmektedir. Ruiter ve arkadaşları (2011) ${ }^{[29]}$ yaptıkları çalışmada IPAH'da demir eksikliği \%43'lük bir prevalansla tanımlanmıştır. IPAH'lı hastaların \%44'ünde oral demire verilen küçük tepki, demir emilimi veya salınmasında problem olduğunu göstermektedir.

4. Gebelik ve Korunma: Şiddetli PH olan hastalarda gebelikte yüksek maternal mortalite riski bildirilmiştir (\%17-50). Çoğu ölüm gebeliğin son üç ayında ve özelikle doğumdan sonraki günlerde, haftalarda, aylarda, pulmoner hipertansif krizler, sağ kalp yetersizliği veya trombotik olaylarla ilişkili olarak ortaya çıkmaktadır. Daha şiddetli PH olan hastalar daha yüksek komplikasyon riski taşıyor olsa da daha hafif $\mathrm{PH}$ olan hastalarda risk altındadır. Gebelik PH'ın ilerlemesini tetikleyebilir. $\mathrm{PH}$ hastaları bu konuda eğitilmelidir. ${ }^{[28]}$ Gebe kalan hastalara gebeliğin yüksek riskli olduğu açıklanmalı ve gebeliği sonlandırma konusu hasta ile tartışılmalıdır. ${ }^{[15]}$ Hasta tarafından hangi seçenek seçilmiş olursa olsun, multidisipliner uzman bakımı esastır. ${ }^{[28]}$ Bedard 
ve arkadaşları (2009)[30], 1997-2007 yılları arasında yaptıkları sistematik rewiev çalışmasında mortalite oranlarını idiyopatik PAH'da \%17, konjenital kalp hastalıkları ile ilişkili PAH'da \%28 ve etiyolojik PH'da \%33 bulmuşlar, ölümlerin \%78'inin doğumdan sonraki ilk ay içinde meydana geldiğini, primigravidalar ve genel anestezi alan gebelerin ölüm risklerinin daha yüksek olduğunu saptamışlardır.

En uygun doğum kontrolü konusunda yeterli görüş bulunmamakla beraber hastanın PH tedavisinde kullandığı ilaçlar yöntem seçmede etkilidir. Tolere edilemeyen menopoz semptomları bulunan $\mathrm{PH}^{\prime}$ ı kadınlarda hormon tedavisinin antikoagülanla birlikte uygulanması düşünülebilir. ${ }^{[15]}$

5. Aşılama: Göğüs enfeksiyonlarına karşı tüm $\mathrm{PH}^{\prime}$ lı hastaların pnömokok ve influenzaya yönelik aşılanması önerilir. ${ }^{[27,28]}$ Göğüs enfeksiyonları genellikle bu hastalarda sağ ventrikül yetersizliği veya sepsis yolu ile semptomlarda şiddetlenmeye yol açabilir. ${ }^{[28]}$

6. Seyahat: Uzun süreli uçuşlarda oksijen desteği gerekip gerekmediği konusunda yeterli çalışmalar yoktur. Fakat hipoksi belirtileri düşünüldüğünde DSÖ-FS III-IV hastalarda ve arteriyal oksijen basıncı sürekli $<8 \mathrm{kPa}$ $(60 \mathrm{mmHg})$ olan hastalar için uçuş esnasında oksijen desteği düşünülmelidir. Bu hastalar oksijen desteği olmadan 1500-2000 metrenin üzerine çıkmamalıdır. $\mathrm{PH}$ hastalarının seyahati sırasında hastalıklarına ilişkin verileri yazılı olarak yanlarında bulundurmaları tavsiye edilmeli; seyahat edecekleri bölge ile ilgili iletişim kurabilecekleri en yakın sağlık kuruluşları konusunda rehberlik edilmelidir. ${ }^{[15]}$

7. Psikososyal Destek: Uzmanlaşmış kişilerce hasta/ailesi ve arkadaşlarını da kapsayan sosyal destek ve eğitim programlarına katılımı tavsiye edilir. ${ }^{[27]}$

8. PH Dernekleri: $\mathrm{PH}$ hastalarının yarısından fazlası ve bakıcıların 1/3'i; aile, arkadaşlar ve toplum arasında hastalığın anlaşılmaması nedeniyle sosyal olarak izole edilmiştir. Hasta dernekleri PH hastalarının yönetiminde önemli bir varlıktır. Hasta dernekleri ağ oluşturma, toplantılar ve sosyal aktiviteler için fırsatlar sunar. Ayrıca hasta savunuculuğunu destekler. Yardım hatları, mesaj panoları ve sosyal medya kanalları sağlar. Hasta dernekleri ile multidisipliner sağlık ekipleri arasında yakın bağlantıları ve etkin iletişimi sürdürmek, hizmetlerin, desteğin ve kaynakların en iyi şekilde koordine edilmesini sağlar. ${ }^{[31]}$

\section{PH'da Hemşirelik Bakımı}

Hemşirelerin PH hastasının bakımında hasta ve hekim arasında koordinasyon rolü vardır. Hemşire, ilaca uyum, beslenme, egzersiz, mental sağlık ve palyatif bakımda önemli role sahiptir. ${ }^{[9]}$
Hemşirelik bakımının amaçları;

- Kardiyopulmoner fonksiyonları en üst seviyeye çıkarmak,

- İstirahatı sağlamak,

- Farmakolojik tedavinin etkilerini değerlendirmek,

- Uygun beslenmeyi sağlamak,

- Cilt bütünlüğünü sürdürmek,

- Kalp yetersizliği hakkında hasta ve ailesinin eğitimini gerçekleştirmektir. ${ }^{[32]}$

PH hastalarında hemşirelerin görevleri;

\section{Bakımın Koordinasyonu:}

a. Teşhis sırasında yapılacak testlerin koordine edilmesi,

b. Tanı konulduktan ve ilk tedaviye başlandıktan sonra doz ayarlama ve ek tedavi ihtiyacına yönelik rehberlik sağlama. ${ }^{[9]}$

c. PH hastalarının oral, inhaler veya intravenöz tedavilerinde eğitim, izleme ve destek sürecinde rol alma. ${ }^{[28]}$

d. Hasta verilerini yorumlama, karar verme ve uygun önlemleri alma,

e. Yatarak veya ayaktan tedavi gören hastaları koordine etme, taburcu etme. ${ }^{[33]}$

f. Destek gruplarının organizasyonunu sağlama. ${ }^{[9]}$

\section{Değerlendirme ve Girişim:}

a. Geçmişteki sağlık öyküsü konusunda veri toplama,

b. Sağ kalp yetersizliğini değerlendirme, uygun şekilde girişimde bulunma,

c. İlaçlara verilen yanıtı değerlendirme, yan etkileri gözlemleme ve yönetme,

d. Tedaviye uyumu değerlendirme,

e. Eleştirel düşünme, problem çözme ve hasta gereksinimlerini belirleme. ${ }^{[33]}$

\section{Eğitim ve Araştırma:}

a. Hastalık durumu, teşhis, tedavi seçenekleri, ilaç kullanımı-yararları, yan etkileri ve genel hasta yönetimi konusunda hasta ve personel eğitimlerini uygulama,

b. Hastanın öz -bakım becerilerini, hastalık yönetimini (kalp yetersizliği belirtileri, su-sodyum alımı) sağlama,

c. Hasta bakım sonuçlarını desteklemek/iyileştirmek için araştırmalar yapma.

\section{Savunma:}

a. Hastanın hastalığa uyum sağlamasına, baş etme becerilerini geliştirmesine yardımcı olma,

b. Bakım hedeflerini iyileştirme,

c. Hasta savunucusu olma, etkili iletişim sağlama,

d. Psikososyal durumu, finansal kaynakları tanımlama ve uygun finansal kaynaklara başvurma. ${ }^{[33]}$ 


\section{Sağlık Personeli Eğitimi}

Sağlık personeli eğitimi, karmaşık tıbbi rejimler gerektiren kronik bir hastalığı yönetmek için gereklidir. PH hastalarının tedavi gördüğü kliniklerde çalışan hemşire ve hekimler $\mathrm{PH}$ ve sağ kalp yetersizliği yönünden eğitilmelidir. Ayrıca sağ kalp yetersizliği ve infüze edilen prostasiklinler ile ilgili acil durum hazırlığı konusunda eğitim hizmetleri sağlanmalıdır. Bu alanlar acil servis, girişimsel radyoloji, genel cerrahi, kardiyak kateterizasyon laboratuvarı vb. alanları ve bu alanlarda çalışanları kapsamaktadır. $\mathrm{PH}^{\prime}$ lı hastaların yatarak tedavi gördüğü kliniklerde ve yoğun bakım ünitelerindeki hemşireler düzenli olarak hizmet içi eğitime alınmalıdır. Bu hemşirelere prostasiklin uygulamasında dikkat edilecek hususlar, venöz giriş bölgeleri, infüzyon pompa eğitimleri ve hasta transferi konuları anlatılmalıdır. Illaç hatalarının önlenmesi için, ilaç konsantrasyonları, infüzyon hızları ve tedavi dozları doğru bir şekilde uygulanmalıdır. ${ }^{[33]}$

\section{Hemşirelik Tanıları}

- Preload artışı/azalması, Afterload artışı, Miyokart kontraktilitesinde artış/azalma Aritmiler nedeniyle Kalp Debisinde Azalma. ${ }^{[32]}$

- Alveokapiller alanda sıvı birikimine bağlı Gaz Alışverişinde Bozulma. ${ }^{[34]}$

- Ölüm korkusu, tanı testleri, tanı ve tedavilerin anlaşılmaması nedeniyle Anksiyete-Korku. ${ }^{[32]}$

- Renal perfüzyonun azalması sonucu antidiüretik hormon (ADH) ve aldosteron düzeylerinin yükselmesi, sıvı volümünde artış, onkotik basınçta azalmanın neden olduğu Sıvı Volüm Fazlalığı. ${ }^{[32]}$

- Diüretik tedavinin etkisiyle vücuttan su ile birlikte sodyum ve potasyumun aşırı atılması, sodyum içeriği düşük diyet, total vücut sıvılarının artması sonucu dilüe elektrolit konsantrasyonu, nedeniyle Elektrolit Dengesizliği. ${ }^{[32]}$

- Doku perfüzyonunun bozulmasıyla besinlerin emiliminde bozulma, yetersiz oral alım, iştahta azalma, bulantı, halsizlik, nefes darlığı ve diyetini sevmeme nedeniyle Beslenmede Değişiklik: Vücut Gereksiniminden Daha Az Beslenme. ${ }^{[32]}$

- Alveolar gaz değişiminin bozulması ve kardiyak outputun azalması sonucu doku hipoksisi, yetersiz beslenme, uykusuzluk, nefes darlığı, korku ve anksiyete nedeniyle Aktivite İntoleransı. ${ }^{[32]}$

- Ödem, yetersiz doku perfüzyonu ve yetersiz beslenme durumuyla ilişkili deri hasarında artma nedeniyle Deri Bütünlüğünde Bozulma Riski. ${ }^{[32]}$

- Anksiyete, korku veya nefes darlığı, ortam değişikliği, fiziksel harekette azalma, sık tanı tedavi yapılması, or- topne nedeniyle alışılmış uyku pozisyonunu sağlamada yetersizlik nedeniyle uyku düzeninde bozulma. ${ }^{[32]}$

- Halsizlik, kardiyak outputta azalma ve ACE inhibitörleri, diüretikler gibi bazı ilaçların hipotansif etkilerinden kaynaklanan serebral perfüzyonda azalma sonucu baş dönmesi, senkop, huzursuzluk, ajitasyon, unutkanlık, konfüzyon ve yardımsız kalkma sebebiyle yaralanma riski. ${ }^{[32]}$

\section{Sonuç}

PH'da görülen semptomlar ciddi olup, yaşamı tehdit etmektedir. Çalışmalarda PH hastalarının sağlıkla ilgili yaşam kalitesinin önemli ölçüde bozulduğu ve hastalarda anksiyete, depresyon gibi ruhsal bozuklukların sık görüldüğü bildirilmiştir.

$\mathrm{PH}$ yaşamı sınırlamakta ve hastalar yaşam kalitesini azaltan birçok semptomla karşı karşıya kalmaktadır. PH'un tedavi ve bakımı kompleks olup genellikle palyatiftir. Tedavinin ve bakımın amacı; morbidite ve mortaliteyi azaltmak, semptomları ve fonksiyonel durumu iyileştirmektir. Hemşireler kardiyopulmoner fonksiyonları en üst seviyeye çıkarmak, kalp yetersizliği hakkında hasta ve ailesini eğitmek, tedavi ve bakımı uygulamak, farmakolojik tedavinin etkilerini değerlendirmek, uygun beslenmeyi sağlamak, cilt bütünlüğünü sürdürmek ve semptomların yönetiminde önemli rollere sahiptir. PH 'da hemşirelik yönetimi ile ilgili kanıt temelli çalışmalar yapılması hemşirelik bakım ve uygulamaları açısından faydalı olacaktır.

\section{Hakem Değerlendirmesi: Dış bağımsız.}

Çıkar Çatışması: Yazarlar arasında herhangi bir çıkar çatışması bulunmamaktadır.

Yazarlık Katkıları: Konsept: S.Ü.; Dizayn: S.Ü., Ö.Ö., E.Y.B.;Veri Toplama veya İşleme: S.Ü., Ö.Ö., E.Y.B.; Analiz veya Yorumlama: S.Ü., Ö.Ö., E.Y.B.; Literatür Arama: Ö.Ö., E.Y.B.; Yazan: Ö.Ö., E.Y.B., S.Ü.

\section{Kaynaklar}

1. Öztürk Ö, Şahin Ü. Pulmoner Arteriyel Hipertansiyon: Tanı ve Tedavisi. Süleyman Demirel Üniversitesi Tıp Fakültesi Dergisi 2009;16:39-47.

2. Purcell HJ, Kalra PR. Pulmoner Hipertansiyon. In: Ilerigelen B. çev. Kardiyoloji. 1. Baskı. İstanbul: İstanbul Tıp Kitabevi; 2009. s. 276-86.

3. Peacock AJ, Murphy NF, McMurray JJ, Caballero L, Stewart S. An epidemiological study of pulmonary arterial hypertension. Eur Respir J 2007;30:104-9.

4. McGoon MD, Benza RL, Escribano-Subias P, Jiang X, Miller DP, Peacock $A J$, et al. Pulmonary arterial hypertension: epidemiology and registries. [Article in Turkish]. Turk Kardiyol Dern Ars 2014;42 Suppl 1:67-77.

5. McGoon MD, Miller DP. REVEAL: a contemporary US pulmonary arterial hypertension registry. Eur Respir Rev 2012;21:8-18. 
6. Humbert M, Sitbon O, Chaouat A, Bertocchi M, Habib G, Gressin V, et al. Pulmonary arterial hypertension in France: results from a national registry. Am J Respir Crit Care Med 2006;173:1023-30.

7. Pektaş MB, Pektaş A, Emren SV, Aldemir M, Özkeçeci G, Kula $S$, et al. An Epidemiological Study of Pulmonary Hypertension In Turkish Adults. Mustafa Kemal Üniversitesi Tıp Dergisi 2015;6(:24-31.

8. Housten-Harris T. The nurse specialist and practical issues in the care of pulmonaryarterial hypertension patients. Int J Clin Pract Suppl 2007;61:10-8.

9. Wapner J, Matura LA. An Update on Pulmonary Arterial Hypertension. J Nurse Pract 2015;11:551-9.

10. Wilkens H, Grimminger F, Hoeper M, Stähler G, Ehlken B, Plesnila-Frank $C$, et al. Burden of pulmonary arterial hypertension in Germany. Respir Med 2010;104:902-10.

11. Taichman DB, Shin J, Hud L, Archer-Chicko C, Kaplan S, Sager JS, et al. Health-related quality of life in patients with pulmonary arterial hypertension. Respir Res 2005;6:92.

12. Kukkonen M, Puhakka A, Halme M. Quality of life among pulmonary hypertension patients in Finland. Eur Clin Respir J 2016;3:26405.

13. Poms A, Kingman M. Inhaled treprostinil for the treatment of pulmonary arterial hypertension. Crit Care Nurse 2011;31:e1-10.

14. Kaymaz C, Mutlu B, Küçükoğlu MS, Kaya B, Akdeniz B, Kılıçkıran Avcı B, et al. Preliminary results from a nationwide adult cardiology perspective for pulmonary hypertension: RegiStry on cllnical outcoMe and sUrvival in pulmonaRy hypertension Groups (SIMURG). Anatol J Cardiol 2017;18:242-50.

15. Galiè N, Hoeper MM, Humbert M, Torbicki A, Vachiery JL, Barbera JA, et al; Task Force for Diagnosis and Treatment of Pulmonary Hypertension of European Society of Cardiology (ESC); European Respiratory Society (ERS); International Society of Heart and Lung Transplantation (ISHLT). Guidelines for the diagnosis and treatment of pulmonary hypertension. Eur Respir J 2009;34:1219-63.

16. Küçükoğlu MS, Sinan ÜY. The new insights of 2015 ESC Pulmonary Hypertension Guidelines. [Article in Turkish]. Turk Kardiyol Dern Ars 2016;44:4-8.

17. Souza R, Paulo S, Simonneau G. Classification of Pulmonary Hypertension, Advances İn Pulmonary Hypertension 2014;13:17-20.

18. Smith CS, York NL, Kane CJ, Weitendorf F. Care of the patient with pulmonary arterial hypertension. Dimens Crit Care Nurs 2015;34:340-7.

19. Escribano-Subias P, Blanco I, López-Meseguer M, Lopez-Guarch CJ, Roman A, Morales P, et al; REHAP investigators. Survival in pulmonary hypertension in Spain: insights from the Spanish registry. Eur Respir J 2012;40:596-603.
20. Souza R, Humbert M, Sztrymf B, Jaïs X, Yaïci A, Le Pavec J, et al. Pulmonary arterial hypertension associated with fenfluramine exposure: report of 109 cases. Eur Respir J 2008;31:343-8.

21. Strange G, Fowler R, Jary C, Dalton B, Stewart S, Gabbay E. Integrated care and optimal management of pulmonary arterial hypertension. J Multidiscip Healthc 2009;2:67-78.

22. Gürses D, Gül Ö. Evaluation of Clinical, Epidemiological and Hemodynamic Data of Our Patients with Pulmonary Hypertension. Guncel Pediatr. 2018;16(1):19-28.

23. Akdeniz B. Son Çalışmalar ve Kılavuzlar Işığında Pulmoner Hipertansiyon Tedavisi. Turkiye Klinikleri J Cardiol-Special Topics 2016;9:29-40.

24. Nieves JA, Kohr L. Nursing considerations in the care of patients with pulmonary hypertension. Pediatr Crit Care Med 2010;11:S74-8.

25. Mirici A, Gönlügür U. Pulmoner Hipertansiyonda Medikal Tedavi. Nobel Medicus 2011;7:05-11.

26. Gunt C, Çekmen N. Pulmonary Hypertension and Weaning. J Turk Soc Intens Care 2016;14:68-79.

27. Şen Selimoğlu H.. İdyopatik Pulmoner Arter Hipertansiyonu Tedavisi: Güncel Durum ve Gelecekteki Yönelişler. Güncel Göğüs Hastalıkları Serisi 2015;3:100-18.

28. Dimopoulos K., Harries C, Parfitt L. The Spectrum of Pulmonary Arterial Hypertension in Adults with Congenital Heart Disease: Management from a Physician and Nurse Specialist Perspective. Journal of Congenital Cardiology 2017;1:1-9.

29. Ruiter G, Lankhorst S, Boonstra A, Postmus PE, Zweegman S, Westerhof $\mathrm{N}$, et al. Iron deficiency is common in idiopathic pulmonary arterial hypertension. Eur Respir J 2011;37:138691.

30. Bédard E, Dimopoulos K, Gatzoulis MA. Has there been any progress made on pregnancy outcomes among women with pulmonary arterial hypertension? Eur Heart J 2009;30:256-65.

31. Graarup J, Ferrari P, Howard LS. Patient engagement and self-management in pulmonary arterial hypertension. Eur Respir Rev 2016;25:399-407.

32. Enç N, Yiğit Z, Altıok MG, Özer S, Oğuz S. Kalp Yetersizliği Akut Koroner Sendromlar Hipertansiyon Hemşirelik Bakım Kılavuzu, Türk Kardiyoloji Derneği. Available at: http://file.tkd.org.tr/ kilavuzlar/ulusal/2007_kalp_yetersizligi_akut_koroner_sendromlarda_hipertansiyon_hemsirelik_bakim_kilavuzu.pdf. Accessed August 8, 2018.

33. Stewart T, Burks M, Nolley SH, Hill W, Housten T, Kennedy $\mathrm{K}$, et al. Collaborative Care: A Defining Characteristic for a Pulmonary Hypertension Center. Pulmonary Therapy 2017;3:93-7.

34. Badır A. Kalp Hastalıklarına Bağlı Komplikasyonlar. In: Karadakovan A, Aslan FE, editors. Dahiliye ve Cerrahi Hastalıklarda Bakım. Ankara: Akademisyen Kitabevi; 2017. p. 504-507. 